\title{
Genetic and epigenetic alterations on the short arm of chromosome II are involved in a majority of sporadic
}

\section{Wilms' tumours}

\section{Y Satoh ${ }^{1,2}$, H Nakadate ${ }^{3}$, T Nakagawachi ${ }^{1,4}, K_{\text {Higashimoto', K Joh', Z Masaki }{ }^{2}, \text { J Uozumi }^{2}, \text { Y Kaneko }}^{5}$, T Mukai' and $H$ Soejima ${ }^{*}$,}

'Division of Molecular Biology and Genetics, Department of Biomolecular Sciences, Faculty of Medicine, Saga University, 5- I-I Nabeshima, Saga 849-850 I, Japan; ' ${ }^{2}$ epartment of Urology, Faculty of Medicine, Saga University, 5-I - I Nabeshima, Saga 849-850 I, Japan; ${ }^{3}$ Department of Pediatrics, Kitasato University Hospital, I-15-I Kitasato, Sagamihara, Kanagawa 228-8555, Japan; ${ }^{4}$ Department of Surgery, Faculty of Medicine, Saga University, 5-I - I Nabeshima, Saga 849-850 I, Japan; ${ }^{5}$ Saitama Cancer Center, Research Institute for Clinical Oncology, 8 I 8 Komuro, Ina, Saitama 362-0806, Japan

\begin{abstract}
Wilms' tumour is one of the most common solid tumours of childhood. I I I 3 (WTI locus) and I I I 5.5 (WT2 locus) are known to have genetic or epigenetic aberrations in these tumours. In Wilms' tumours, mutation of the Wilms tumour I (WTI) gene at the WTI locus has been reported, and the WT2 locus, comprising the two independent imprinted domains IGF2/HI9 and KIP2/LITI, can undergo maternal deletion or alterations associated with imprinting. Although these alterations have been identified in many studies, it is still not clear how frequently combined genetic and epigenetic alterations of these loci are involved in Wilms' tumours or how these alterations occur. To answer both questions, we performed genetic and epigenetic analyses of these loci, together with an additional gene, CTNNBI, in 35 sporadic Wilms' tumours. Loss of heterozygosity of I I I 5.5 and loss of imprinting of IGF2 were the most frequent genetic (29\%) and epigenetic (40\%) alterations in Wilms' tumours, respectively. In total, $83 \%$ of the tumours had at least one alteration at II PI5.5 and/or II p 3. One-third of the tumours had alterations at multiple loci. Our results suggest that chromosome II $\mathrm{p}$ is not only genetically but also epigenetically critical for the majority of Wilms' tumours.

British Journal of Cancer (2006) 95, 54I-547. doi:10.1038/sj.bjc.6603302 www.bjcancer.com
\end{abstract}

Published online 8 August 2006

(c) 2006 Cancer Research UK

Keywords: Wilms' tumour; genetics; epigenetics; loss of heterozygosity; loss of imprinting; DNA methylation

Wilms' tumour, also known as nephroblastoma, is one of the most common solid tumours of childhood, accounting for approximately $6 \%$ of all childhood malignancies. Chromosomal region 11 p13 was first identified as a Wilms' tumour locus, WT1, because the region was found to be deleted in Wilms' tumours (Kaneko et al, 1981; Huff, 1998; Dome and Coppes, 2002, OMIM 194070). The Wilms tumour 1 (WT1) gene, isolated from the WT1 locus, was the first causative gene for Wilms' tumour (Call et al, 1990; Gessler et al, 1990). However, WT1 aberrations, such as deletions and point mutations, are observed in only approximately $10-20 \%$ of Wilms' tumours (Huff, 1998; Nakadate et al, 2001). The small number of WT1 mutations in Wilms' tumours suggests that WT1 can be inactivated by alterations that would not be detected by mutational analysis (Huff, 1998). On the other hand, although WT1 mutation is not frequent, $W T 1$ mutation and CTNNB1 ( $\beta$-catenin) mutation at 3 p21 are significantly correlated with Wilms' tumours (Maiti et al, 2000).

Loss of heterozygosity $(\mathrm{LOH})$ of $11 \mathrm{p} 15.5$, which is known as the WT2 locus (OMIM 194071), is observed in Wilms' tumours. LOH occurs on the maternal chromosome, suggesting the involvement of genomic imprinting in Wilms' tumorigenesis. This imprinted region is well characterised, and is divided into two imprinted

*Correspondence: Dr H Soejima; E-mail: soejimah@med.saga-u.ac.jp Received 2 February 2006; revised 3 July 2006; accepted 7 July 2006; published online 8 August 2006 domains, IGF2/H19 and KIP2/LIT1 (Feinberg, 2000). It has been reported that IGF2 and $H 19$ within the IGF2/H19 domain are expressed abnormally in Wilms' tumours. IGF2 encodes an embryonal growth factor and is transcribed exclusively from the paternal allele (Reik and Murrell, 2000), and H19 is a noncoding RNA with reciprocal transcription from the maternal allele. In Wilms' tumours, abnormally high levels of IGF2 mRNA and loss of imprinting (LOI) of IGF2, allowing both paternal and maternal alleles to be transcribed, have been observed (Reeve et al, 1985; Ogawa et al, 1993; Rainier et al, 1993). LOI of IGF2 is always accompanied by $H 19$ biallelic hypermethylation, leading to inactivation of $H 19$ (in the normal situation, the region upstream of $\mathrm{H} 19$ is methylated only on the paternal allele) (Moulton et al, 1994; Steenman et al, 1994). Demethylation of DMR-LIT1, an imprinting control region (ICR) of the KIP2/LIT1 domain, occurs in half of all patients with Beckwith - Wiedemann syndrome (BWS) (OMIM 130650), which predisposes patients to embryonal tumours, and in a variety of adult tumours. The $p 57^{K I P 2}$ (KIP2)/ CDKN1C gene within the KIP2/LIT1 domain, which is expressed predominantly from the maternal allele, encodes a cyclindependent kinase inhibitor and is a putative tumour suppressor. In several adult tumours, KIP2 expression is epigenetically reduced (Shin et al, 2000; Kikuchi et al, 2002; Li et al, 2002; Soejima et al, 2004). However, KIP2 expression has been found to be reduced in Wilms' tumours in some studies, but not in others (Chung et al, 
A Chromosome 11
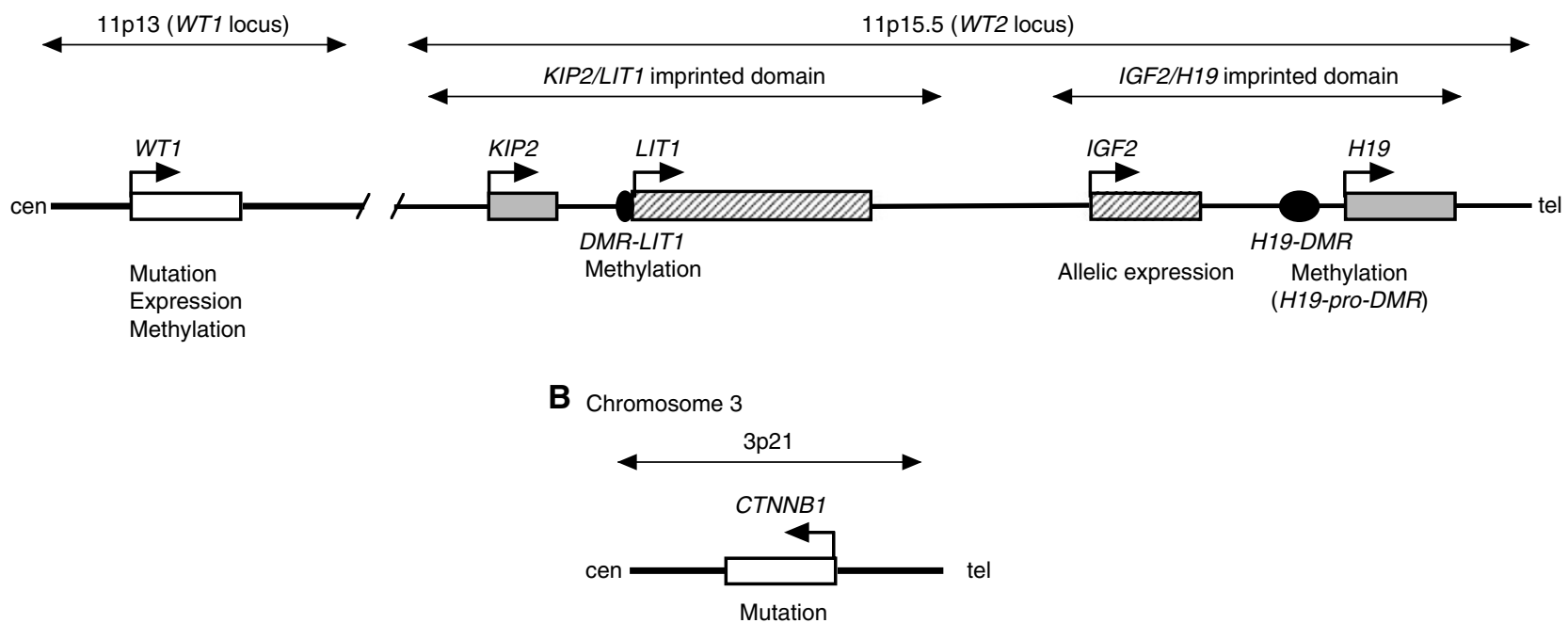

Figure I Maps of regions analysed in this study. (A) WTI locus and WT2 locus on the short arm of chromosome II. Representative genes are shown. Broken arrows indicate transcriptional direction. Grey boxes and shaded boxes indicate maternal and paternal expression, respectively. DMR-LITI and HI9-DMR are the ICRs for each domain, respectively. DMR-LITI is differentially methylated on the maternal allele. The HI9-DMR and HI9 promoter are differentially methylated on the paternal allele. The items examined in this study are shown below each gene or DMR. (B) CTNNBI locus. Maps are not to scale.

1996; Hatada et al, 1996; Thompson et al, 1996; O’Keefe et al, 1997; Taniguchi et al, 1997; Soejima et al, 1998).

Although several genes involved in Wilms' tumour have been identified, as described above, the alteration frequencies of these genes (loci) and how many loci are altered in the tumour are still unknown. To investigate this, we comprehensively investigated genetic and epigenetic alterations of three loci - WT1 (11p13), WT2 (11p15.5), and CTNNB1 (3p21) - in 35 sporadic Wilms' tumours (Figure 1). Our data indicate that genetic and/or epigenetic alterations of genes at these loci, especially WT1 and WT2, is involved in the majority of Wilms' tumours, and that alterations of multiple loci occur in one-third of tumours. These findings suggest that genetic and epigenetic alterations on the short arm of chromosome 11 play an important role in Wilms' tumorigenesis.

\section{MATERIALS AND METHODS}

\section{DNA and RNA}

In all, 35 tissue samples from sporadic Wilms' tumours and five tissue samples from mid-gestational fetal kidneys were obtained from Saitama Cancer Center Hospital (Saitama, Japan) and the fetal tissue bank at the University of Washington, (WA, USA), respectively. Genomic DNA and total RNA were extracted with a QIAamp DNA mini kit (Qiagen, Hilden, Germany) and Isogen (Nippon Gene, Tokyo, Japan), respectively.

\section{Mutation and $\mathrm{LOH}$ analyses}

Genetic analyses of $W T 1$ were carried out as previously described (Nakadate et al, 1999, 2001). Briefly, WT1 loci were screened for mutations by single-strand conformation polymorphism (SSCP) analysis of all exons and splice-donor/acceptor sites. When an aberrant band was identified by SSCP, the band was excised and sequenced. Loss of heterozygosity was also analysed using polymorphic DNA markers as follows to compare tumour tissue with adjacent normal tissue or peripheral blood: D11S16, D11S325, PAX6, D11S324, WT1, and CAT for $11 \mathrm{p} 13$; and D11S12, D11S922, D11S932, IGF2, INS, and TH for 11p15.5. Mutations in exon 3 of the CTNNB1 gene were investigated by PCR-directed sequencing as previously described (Satoh et al, 2003).

\section{Quantitative real-time reverse transcription (RT) - polymerase chain reaction (PCR)}

Total RNA (500 ng) was treated with RNase-free DNase I (Roche, Basel, Switzerland) and reverse-transcribed with ReverTra Ace reverse transcriptase (Toyobo, Japan) and random primers (TaKaRa, Japan). Quantitative real-time RT-PCR was performed with the LightCycler ${ }^{\mathrm{TM}}$ system (Roche) according to the manufacturer's protocol. The expression of WT1 was normalised with that of $\beta$-actin, as previously described (Satoh et al, 2003). The average WT1 expression of four mid-gestational fetal kidneys was employed as a standard. All experiments were performed in triplicate.

\section{Allele-specific expression of IGF2}

Genotyping of IGF2 was performed by PCR-restriction fragment length polymorphism (RFLP) using a polymorphic HaeIII (ApaI or AvaII) site in exon 9, as previously described (Soejima and Yun, 1998). To eliminate genomic DNA contamination, the RNAspecific product $(1120 \mathrm{bp})$ was amplified by using an exon connection primer pair (5'-TCCTGGAGACGTACTGTGCTA-3' and $5^{\prime}$-GGTCGTGCCAATTACATTTCA-3' ${ }^{\prime}$ ). To further eliminate contaminating DNA, the RNA-specific product was excised from $1 \%$ agarose gel after electrophoresis and purified. Then, the purified product was subjected to nested PCR and RFLP analysis with HaeIII (Yun et al, 1999).

\section{Methylation analyses}

Combined bisulphite restriction analyses (COBRA) using the hot-stop method were employed to determine the extent of methylation at the differentially methylated region (DMR) of the H19 promoter (H19-pro-DMR), DMR-LIT1, and WT1 promoter. Although an ICR of the IGF2/H19 domain exists between 2 and $5 \mathrm{~kb}$ upstream of the $H 19$ gene, we analysed H19-pro-DMR because IGF2 LOI uniformly correlates with hypermethylation of H19-pro-DMR (Moulton et al, 1994; Steenman et al, 1994). The primer pairs and restriction endonucleases used were as 
follows: $5^{\prime}$-GGGAGGGTTTTGTTTTGATTGGT- ${ }^{\prime}, \quad 5^{\prime}$-ACTCTCCT CCAACACCCCATCTTC-3', and HinfI for H19-pro-DMR; and $5^{\prime}$ CGTATTCGATTTTGTTCGGATTT-3'; 5'-ACTACCCTCAACTTCC CAAAACT-3', and HinfI for the WT1 promoter. For several samples, methylation of H19-pro-DMR was confirmed by using hot-stop COBRA for a region immediately downstream of CTCF binding site 6 (CTCF6) in H19-DMR. The primer pairs and the restriction endonuclease used were $5^{\prime}$-GAGTTYGGGGGTTTTTG TATAGT- $3^{\prime}, 5^{\prime}$-TAAATAATACCCRACCTAAAAATCTAA- $3^{\prime}$, and MluI. DMR-LIT1 was analysed as previously described (Soejima et al, 2004). The hot-stop COBRA products were separated by $7.5 \%$ polyacrylamide gel electrophoresis (PAGE) and quantified with BAS2000 (Fujifilm, Japan). All experiments were performed three times independently.

\section{RESULTS}

Genetic and epigenetic alteration of the IGF2/H19 imprinted domain at $11 \mathrm{p} 15.5$

Of 35 tumours, 10 (29\%) showed LOH of $11 \mathrm{p} 15$ and 25 showed retention of heterozygosity $(\mathrm{ROH})$ at this locus (Tables 1 and 2).
11 p15.5 LOH involved loss of both the IGF2/H19 and KIP2/LIT1 imprinted domains. Although three tumours (\#33, \#34, and \#35) were not informative for polymorphisms, these were considered to have undergone LOH because of hypermethylation of H19-pro$D M R$ and hypomethylation of DMR-LIT1, indicating loss of the maternal chromosomal region. For another three tumours that were not informative for polymorphisms (\#6, \#8, and \#10), methylation of H19-pro-DMR and DMR-LIT1 was maintained, so they were considered to show $\mathrm{ROH}$.

We examined allelic expression of IGF2 to screen for epigenetic alterations of the IGF2/H19 imprinted domain. Genotyping revealed that eight tumours (\#1-4, \#11-14) were heterozygous for polymorphism in IGF2 exon 9. Reverse transcription-PCR revealed that three of these (\#12-14) expressed IGF2 biallelicaly, that is, LOI had occurred (Table 1). We also examined the methylation status of H19-pro-DMR because IGF2 LOI uniformly correlates with biallelic hypermethylation of H19-pro-DMR (Moulton et al, 1994; Steenman et al, 1994). Five normal mid-gestational fetal kidneys were used as controls for the methylation status of H19-pro-DMR. The average percentage methylation of the fetal kidneys was $42.5 \pm 8.4 \%$ (data not shown), and we defined methylation of more than the average of the fetal kidneys +2 s.d.

Table I Genetic or epigenetic alterations in Wilms' tumours

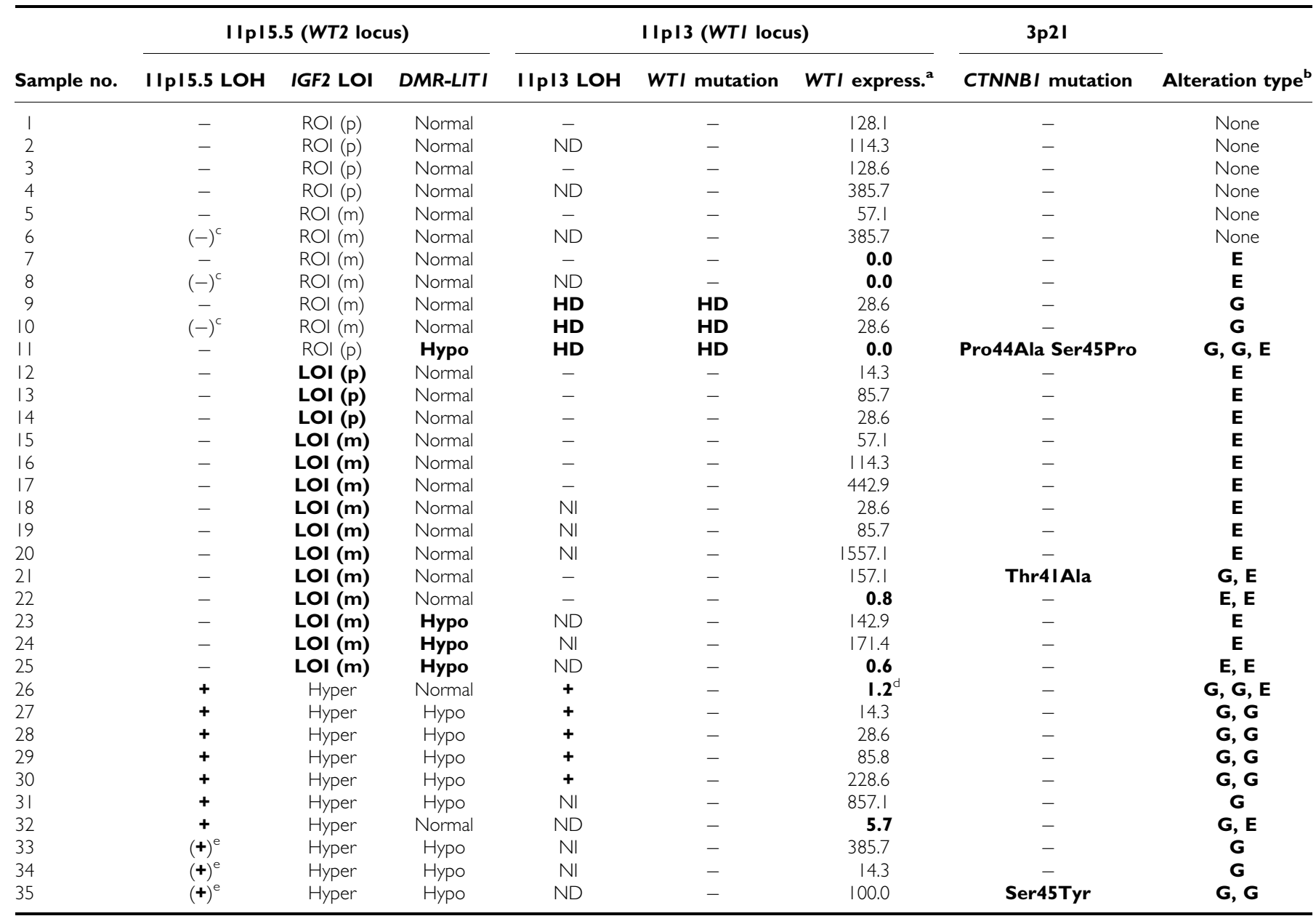

Genetic and epigenetic alterations are indicated by blue and red bold, respectively. IGF2 LOI was examined by RT-PCR-RFLP with Haell polymorphism (p) or methylation analysis of HI 9-pro-DMR (m). Hypermethylation of HI 9-pro DMR in I I I $5.5 \mathrm{LOH}$ cases was not indicated by red color because it was due to LOH. WTI expression in \#I I is not indicated by red color because the reduction of this sample was secondary alteration caused by a genetic alteration, homozygous deletion. LOI=loss of imprinting; hyper = hypermethylation of HI 9-pro DMR; hypo = hypomethylation of DMR-LITI; ND = not done; $\mathrm{NI}=$ not informative; HD = homozygous deletion. ${ }^{\mathrm{a}} W T$ I expression less than $10 \%$ of fetal kidneys is considered epigenetic alteration. ${ }^{b}$ Genetic alteration and epigenetic alteration are indicated by $G$ and $E$, respectively. Number of $G$ or $E$ indicates number of altered loci. 'These were considered $\mathrm{ROH}$ because methylation of HI9-pro-DMR and DMR-LITI were maintained. ${ }^{\mathrm{d}}$ This sample showed promoter hypermethylation. These were considered LOH because of HI 9-pro-DMR hypermethylation and DMR-LITI hypomethylation. 
Table 2 Frequency of each genetic or epigenetic alteration in Wilms' tumours

\begin{tabular}{|c|c|c|c|c|}
\hline Locus & Alteration & $\begin{array}{l}\text { Alteration type (genetic (G) } \\
\text { or epigenetic }(E) \text { ) }\end{array}$ & Sample number & Frequency \\
\hline I I p 5.5 (WT2 locus) & $\begin{array}{l}\text { I Ip } 5.5 \mathrm{LOH} \\
\text { IGF2 LOI } \\
\text { DMR-LITI hypomethylation }\end{array}$ & $\begin{array}{l}G \\
E \\
E\end{array}$ & $\begin{array}{l}26-35 \\
12-25 \\
11,23-25\end{array}$ & $\begin{array}{r}10 / 35(29 \%) \\
14 / 35(40 \%) \\
4 / 35(11 \%)\end{array}$ \\
\hline I|p|3 (WTI locus) & $\begin{array}{l}\text { I I I } 3 \text { LOH } \\
\text { WTI homozygous deletion } \\
\text { WTI reduction }\end{array}$ & $\begin{array}{l}G \\
G \\
E\end{array}$ & $\begin{array}{c}26-30 \\
9-11 \\
7,8,22,25,26^{\mathrm{a}}, 32\end{array}$ & $\begin{array}{l}5 / 20(25 \%) \\
3 / 35(9 \%) \\
6 / 35(17 \%)\end{array}$ \\
\hline $3 p 21$ & CTNNB / mutation & G & $11,21,35$ & $3 / 35(9 \%)$ \\
\hline
\end{tabular}

${ }^{a}$ WTI promoter in \#26 was hypermethylated.
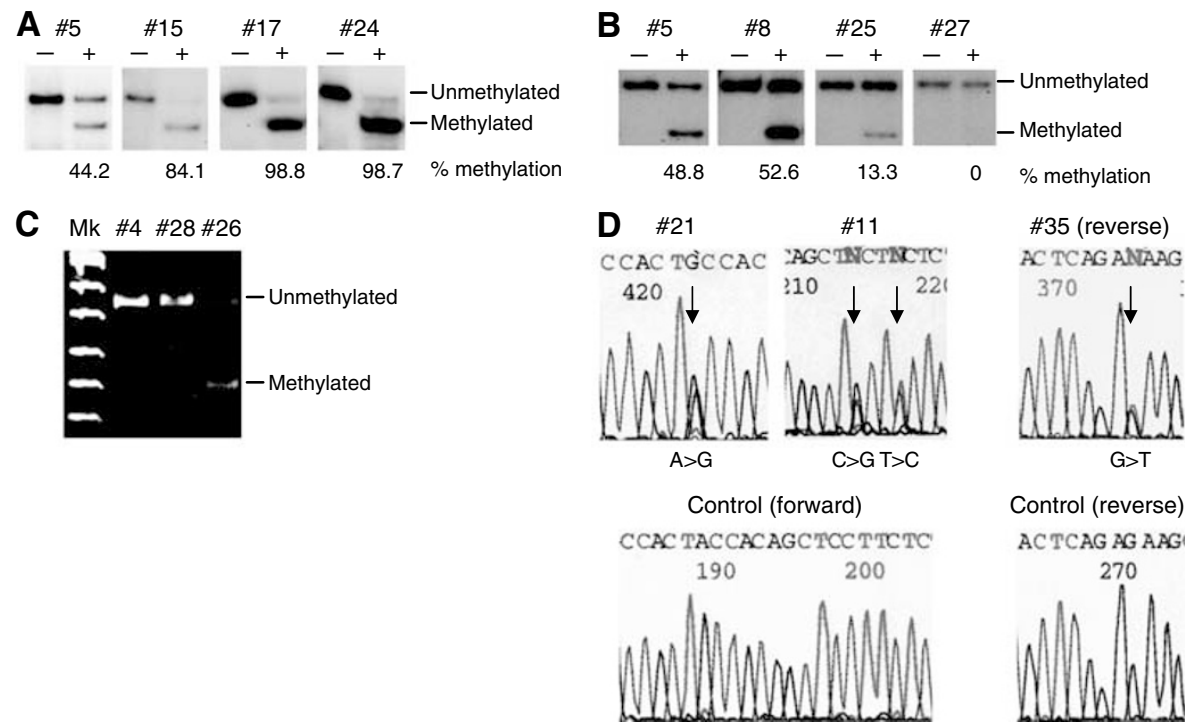

Figure 2 Representative results of this study. (A) Methylation analysis of the HI9-pro-DMR by hot-stop COBRA. Tumour \#5 showed normal methylation, whereas \# I5, \# I7, and \#24 showed hypermethylation. -: not digested by Hinfl, + : digested by Hinfl. (B) Methylation analysis of DMR-LITI by hot-stop COBRA. \#5 and \#8 showed normal methylation, whereas \#25, and \#27 showed hypo- or demethylation. -: not digested by Accll, + : digested by Accll. (C) Methylation analysis of the WTI promoter region by COBRA. \#4 and \#28 showed no methylation, whereas \#26 showed methylation. (D) Mutation analysis of CTNNB I. Arrows indicate bases that were mutated. Control sequences are shown below.

as hypermethylation. The total number of tumours showing H19pro-DMR hypermethylation was 21 , comprising 11 with $\mathrm{ROH}$ and 10 with $\mathrm{LOH}$ (Table 1, Figure 2A). Because LOH occurs with the maternal chromosome, only the methylated paternal chromosome remains in LOH tumour cells, resulting in hypermethylation. Thus, biallelic hypermethylation leading to IGF2 LOI occurred in 11 tumours with ROH. Indeed, all three tumours (\#12, \#13, \#14) that were heterozygous for the polymorphism and showed biallelic expression also showed hypermethylation (data not shown). Furthermore, representative samples with hypermethylation at H19-pro-DMR also underwent hypermethylation at H19-DMR CTCF6 (data not shown). A total of 14 out of 35 tumours $(40 \%)$ had LOI (Tables 1 and 2); and LOI occurred in $56 \%$ of ROH tumours (14 out of 25).

\section{Epigenetic alteration of the KIP2/LIT1 imprinted domain at $11 \mathrm{p} 15.5$}

We investigated methylation of DMR-LIT1 in the KIP2/LIT1 imprinted domain (Tables 1 and 2, Figure $2 \mathrm{~B}$ ) relative to the average percentage methylation in fetal kidneys, which was $44.3 \pm 7.5 \%$ (data not shown). We defined methylation of less than the average of the fetal kidneys - 2 s.d. as hypomethylation. Although 12 tumours, eight with $\mathrm{LOH}$ and four with ROH, showed hypomethylation, the four with $\mathrm{ROH}$ had biallelic hypomethylation because maternal DMR-LIT1 is normally methylated. In spite of LOH, two tumours (\#26 and \#32) did not have a methylation level that was less than the average for the fetal kidneys -2 s.d., but still had a low level of methylation (29.7 and 39.8\%). These findings might be due to contamination with nontumour cells.

We also investigated expression and promoter methylation of $K I P 2$, because this imprinted gene is a putative tumour suppressor gene, but no somatic mutation has been found in tumours to date. KIP2 expression varied from zero to approximately $800 \%$ of that of the control fetal kidneys, and the promoter region was not methylated in any sample (data not shown). In addition, there was no correlation between KIP2 expression and DMR-LIT1 methylation.

A total of $25(71 \%)$ tumours showed alteration of $I G F 2 / H 19$ or KIP2/LIT1 or both of the domains, of which 10 showed LOH, 11 showed IGF2 LOI only, one showed DMR-LIT1 hypomethylation only, and three showed both IGF2 LOI and DMR-LIT1 hypomethylation (Table 1).

\section{Genetic and epigenetic alteration of WT1 at $11 \mathrm{p} 13$}

A total of 20 tumours were informative for polymorphisms on 11p13: 12 of these had preserved heterozygosity and five (25\%) 
showed 11p13 LOH, and these had concurrent 11p15.5 LOH, indicating a large $\mathrm{LOH}$ region (more than $30 \mathrm{Mb}$ ) in the short arm of chromosome 11 (Tables 1 and 2). WT1 gene mutation was also examined as a genetic alteration. Only three tumours had homozygous deletion of $W T 1$, as previously described (Nakadate et al, 1999; Watanabe et al, 2006).

As epigenetic alterations, the expression and promoter methylation of WT1 were examined. We determined the quantity of WT1 expression normalised with $\beta$-actin expression. We defined expression of less than $10 \%$ of that of the control fetal kidneys as a significant reduction, and found seven tumours with such a reduction (Table 1). Two tumours (\#9 and \#10) expressed a certain level of WT1 in spite of a homozygous deletion, which might be due to contamination with nontumour cells. Excluding tumours with homozygous deletions, six tumours $(17 \%)$ had a reduction in WT1 expression (Tables 1 and 2). Methylation analysis, however, revealed that only one tumour (\#26) had promoter methylation, as previously described (Table 1 and Figure 2C) (Satoh et al, 2003). Promoter methylation was not found in any other tumours with reduction in WT1 expression.

In summary, genetic alterations of WT1 such as LOH or WT1 homozygous deletion were found in a total of eight tumours, and epigenetic alterations (i.e. reduction of $W T 1$ expression) were found in six (Table 2).

\section{CTNNB1 mutation}

We found four missense mutations of the CTNNB1 gene in three tumours: Pro44Ala (CCT to GCT) and Ser45Pro (TCT to CCT) in \#11, Thr41Ala (ACC to GCC) in \#21, and Ser45Tyr (TCT to TAT) in \#35 (Tables 1 and 2, Figure 2D). The tumours with CTNNB1 mutation had concurrent WT1 homozygous deletion and DMRLIT1 hypomethylation, IGF2 LOI, and 11p15.5 LOH, respectively.

\section{DISCUSSION}

In this study, we investigated genetic and epigenetic alterations of three loci that are thought to be involved in Wilms' tumour: the WT2 locus (11p15. 5) including the IGF2/H19 and the KIP2/LIT1 imprinted domains, the WT1 locus (11p13) including the WT1 gene, and 3 p 21 locus including the CTNNB1 gene. Loss of heterozygosity of $11 \mathrm{p} 15.5$ was the most frequent genetic alteration (29\%), and IGF2 LOI was the most frequent epigenetic alteration (40\%) (Table 2). In ROH tumours only, IGF2 LOI frequency occurred in approximately $56 \%$ of cases (14/25). The data were consistent with the results of previous reports (Ogawa et al, 1993; Rainier et al, 1993; Steenman et al, 1994; Moulton et al, 1994, Yuan et al, 2005). It is intriguing that three tumours (\#23-25) showed alterations of both IGF2/H19 and KIP2/LIT1 imprinted domains, because each domain is independently regulated, and BWS with both alterations is very rare (DeBaun et al, 2002). Furthermore, \#25 had a reduction of WT1 expression. The data suggest that $11 \mathrm{p}$ is epigenetically unstable in Wilms' tumours. With regard to the number of altered loci, 18 tumours (51\%) showed alteration at only one locus and $11(31 \%)$ showed alterations at multiple loci (Table 3). Six (18\%) tumours did not show any alteration. Thus, $83 \%$ (29 out of 35 ) of Wilms' tumours had alterations at one or more of the three loci. Furthermore, no tumour had mutation of CTNNB1 alone. These results indicate that the alterations observed in Wilms' tumours are concentrated on the short arm of chromosome 11, that is $11 \mathrm{p} 15.5$-p13, and that the region is not only genetically but also epigenetically critical for Wilms' tumorigenesis.

As shown in Figure 3, there were 10 and 15 tumours, respectively, with only genetic or only epigenetic alterations. Four tumours had both genetic and epigenetic alterations. The average age of patients at diagnosis for tumours with only genetic and only

Table 3 Number of altered loci in Wilms' tumour

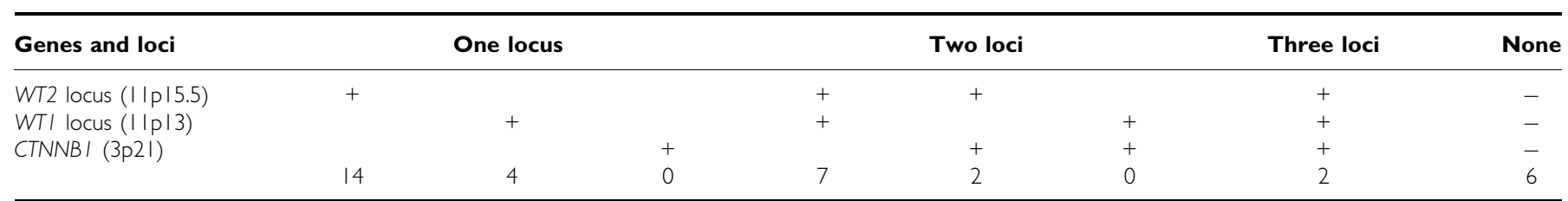

+Indicates genetic or epigenetic alteration at each locus. WT2 locus: I I I 5.5 LOH or IGF2 LOI or DMR-LITI hypomethylation. WTI locus: I I I 3 LOH or WTI mutation or WT I reduction. CTNNB I: mutation.

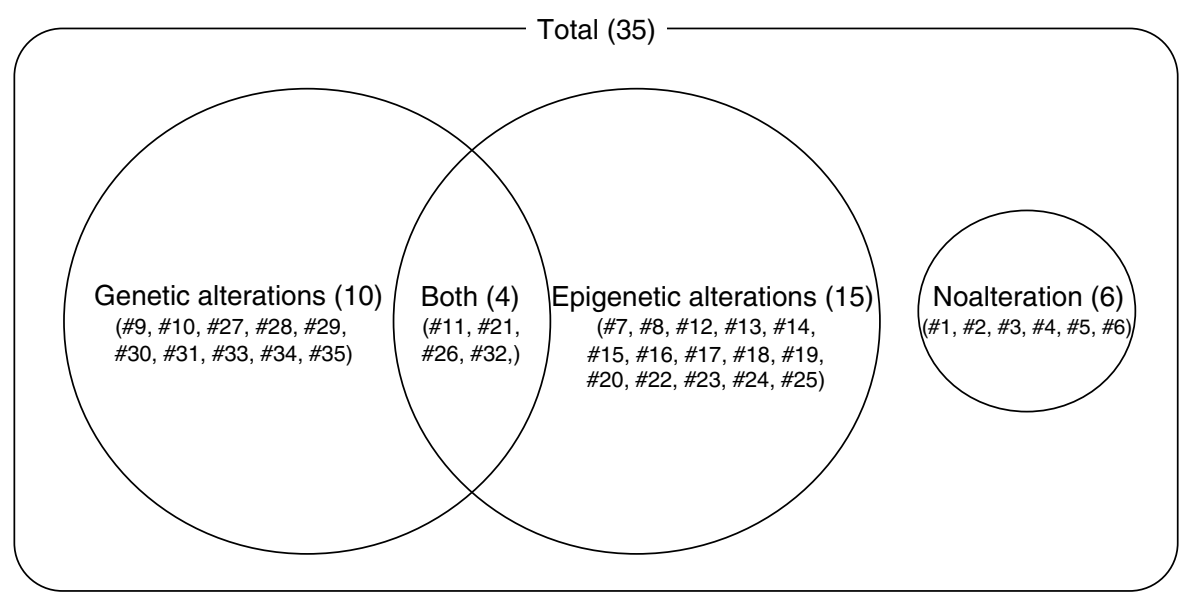

Figure 3 Schematic diagram summarising alterations of the three loci in a total of 35 sporadic Wilms' tumours. Genetic alterations comprise LOH, WTI mutation, and CTNNBI mutation. Epigenetic alterations comprise IGF2 LOI, DMR-LITI hypomethylation, and WTI reduction. 
epigenetic alterations was $34.8 \pm 33.3$ and $46.5 \pm 24.1$ months, respectively, but there was no significant difference between them.

Because maternal LOH of $11 \mathrm{p} 15.5$ is uniformly accompanied by paternal duplication, it results in two paternal copies of the IGF2 gene and an increase of IGF2 expression. In addition, IGF2 LOI is observed in non-neoplastic kidney parenchyma and frequently in early-stage tumours, indicating the importance of IGF2 in Wilms' tumorigenesis (Moulton et al, 1994; Okamoto et al, 1997; Yuan et al, 2005). However, in a recent study, IGF2 LOI was not observed in any of 21 Wilms' tumours from Japanese patients (Fukuzawa et al, 2004). In that study, the HpaII site near the CTCF6 in H19$D M R$, which is approximately $2 \mathrm{~kb}$ upstream from the $H 19$ transcription initiation site, was used to analyse IGF2 LOI using real-time PCR. In the present study, we employed RT-PCR-RFLP and hot-stop COBRA for analysis of the methylation of H19-pro$D M R$. Further, the results of H19-pro-DMR were confirmed by H19-DMR CTCF6 with hot-stop COBRA. Our results clearly show that IGF2 LOI occurs in Japanese patients with Wilms' tumour. At present, we are not able to explain the discrepancy, but having a small sample size might have influenced the results.

Although KIP2 expression is epigenetically reduced in several adult tumours (Shin et al, 2000; Kikuchi et al, 2002; Li et al, 2002; Soejima et al, 2004), expression levels in Wilms' tumour as measured in previous studies have varied (Chung et al, 1996; Hatada et al, 1996; Thompson et al, 1996; O’Keefe et al, 1997; Taniguchi et al, 1997; Soejima et al, 1998). In the present study, KIP2 expression also varied, suggesting that at least in Wilms' tumour, KIP2 may not be involved.

WT1 gene expression was reduced in six (17\%) tumours. It is noteworthy that the frequency of WT1 reduction in expression is similar to that of WT1 mutation. WT1 expression reduction is correlated with predominant stromal histology (Pritchard-Jones et al, 1990; Miwa et al, 1992). Our tumours comprised one stromal, two triphasic, and three blastemal types. Although the precise histologic composition of tumours in the present study was unknown, whether or not there is a correlation between the WT1 expression reduction and histology is not clear because the number of tumours was small. Only one tumour (\#26) had promoter hypermethylation, as described previously (Satoh et al, 2003). Since this tumour also had concurrent 11p13 LOH, 'two-hit' inactivation (LOH and methylation) led to a reduction of WT1 expression. However, methylation was not found in any other tumours with WT1 expression reduction, thus promoter methylation might not be fundamentally involved in WT1 transcriptional repression. WT1 transcriptional regulation is remarkably complex, and our knowledge of it is still quite limited (Englert, 1998). Thus, other unknown mechanisms may be involved in the reduction of WT1 expression.

A highly significant correlation has been found between WT1 mutation and CTNNB1 mutation in Wilms' tumours (Maiti et al, 2000). $\beta$-Catenin, a product of the CTNNB1 gene, is involved in the regulation of cell adhesion and in signal transduction through the WNT pathway. Abrogation of the WNT pathway by CTNNB1 mutations, resulting in reduced serine/threonine phosphorylation, has been recognised as playing an important role in the development of many tumours. All CTNNB1 mutations we found occurred at or near phosphorylation sites. Only one tumour had concurrent homozygous deletion of the WT1 gene. Whether or not there is a correlation between the gene mutations is not clear because the number of tumours with mutations was too small.

In conclusion, genetic and epigenetic alterations of chromosome $11 \mathrm{p}$ play an important role in the majority of Wilms' tumours. There is a possibility that not only the genes investigated in this study but also unidentified genes existing in the region with unknown function also play an important role in Wilms' tumorigenesis. In addition, six tumours did not have any alterations at the three loci studied, suggesting the involvement of genes at other loci. Chromosomes 1p, 4q, 7p, 11q, 14q, 16q, and $17 \mathrm{p}$ are also frequently lost in Wilms' tumours, and the RASSF1A tumour suppressor is frequently silenced by promoter hypermethylation (Ehrlich et al, 2002; Harada et al, 2002; Wagner et al, 2002; Yuan et al, 2005). Identification of a novel gene or genes at these loci and those silenced by epigenetic mechanisms will be helpful to further understand Wilms' tumorigenesis.

\section{ACKNOWLEDGEMENTS}

This study was supported in part by a Grant-in-Aid for Scientific Research on Priority Area 'Applied Genomics' (No. 17019054) from the Ministry of Education, Culture, Sports, Science and Technology of Japan; a Grant-in-Aid for Scientific Research (C) (No. 16590263 and No. 18590313) from the Japan Society for the Promotion of Science; Grants-in-Aid for the Third Term Comprehensive Ten-Year Strategy for Cancer Control from the Ministry of Health, Labour and Welfare, Japan; the Public Trust Surgery Research Fund; an AstraZeneca Research Grant; and The Mother and Child Health Foundation.

\section{REFERENCES}

Call KM, Glaser T, Ito CY, Buckler AJ, Pelletier J, Haber DA, Rose EA, Kral A, Yeger H, Lewis WH (1990) Isolation and characterization of a zinc finger polypeptide gene at the human chromosome 11 Wilms' tumor locus. Cell 60: 509-520

Chung WY, Yuan L, Feng L, Hensle T, Tycko B (1996) Chromosome 11p15.5 regional imprinting: comparative analysis of KIP2 and H19 in human tissues and Wilms' tumors. Hum Mol Genet 5: 1101-1108

DeBaun MR, Niemitz EL, McNeil DE, Brandenburg SA, Lee MP, Feinberg AP (2002) Epigenetic alterations of H19 and LIT1 distinguish patients with Beckwith - Wiedemann syndrome with cancer and birth defects. Am J Hum Genet 70: 604-611

Dome JS, Coppes MJ (2002) Recent advances in Wilms tumor genetics. Curr Opin Pediatr 14: 5-11

Ehrlich M, Jiang G, Fiala E, Dome JS, Yu MC, Long TI, Youn B, Sohn OS, Widschwendter M, Tomlinson GE, Chintagumpala M, Champagne M, Parham D, Liang G, Malik K, Laird PW (2002) Hypomethylation and hypermethylation of DNA in Wilms tumors. Oncogene 21: 6694-6702

Englert C (1998) WT1 - more than a transcription factor? Trends Biochem Sci 23: $389-393$
Feinberg AP (2000) The two-domain hypothesis in Beckwith-Wiedemann syndrome. J Clin Invest 106: 739-740

Fukuzawa R, Breslow NE, Morison IM, Dwyer P, Kusafuka T, Kobayashi Y, Becroft DM, Beckwith JB, Perlman EJ, Reeve AE (2004) Epigenetic differences between Wilms' tumours in white and east-Asian children. Lancet 363: $446-451$

Gessler M, Poustka A, Cavenee W, Neve RL, Orkin SH, Bruns GA (1990) Homozygous deletion in Wilms tumours of a zinc-finger gene identified by chromosome jumping. Nature 343: $774-778$

Harada K, Toyooka S, Maitra A, Maruyama R, Toyooka KO, Timmons CF, Tomlinson GE, Mastrangelo D, Hay RJ, Minna JD, Gazdar AF (2002) Aberrant promoter methylation and silencing of the RASSF1A gene in pediatric tumors and cell lines. Oncogene 21: 4345-4349

Hatada I, Inazawa J, Abe T, Nakayama M, Kaneko Y, Jinno Y, Niikawa N, Ohashi H, Fukushima Y, Iida K, Yutani C, Takahashi S, Chiba Y, Ohishi S, Mukai T (1996) Genomic imprinting of human p57 ${ }^{\text {KIP2 }}$ and its reduced expression in Wilms' tumors. Hum Mol Genet 5: $783-788$

Huff V (1998) Wilms tumor genetics. Am J Med Genet 79: 260-267 
Kaneko Y, Egues MC, Rowley JD (1981) Interstitial deletion of short arm of chromosome 11 limited to Wilms' tumor cells in a patient without aniridia. Cancer Res 41: 4577-4578

Kikuchi T, Toyota M, Itoh F, Suzuki H, Obata T, Yamamoto H, Kakiuchi H, Kusano M, Issa JP, Tokino T, Imai K (2002) Inactivation of $p 57^{K I P 2}$ by regional promoter hypermethylation and histone deacetylation in human tumors. Oncogene 21: $2741-2749$

Li Y, Nagai H, Ohno T, Yuge M, Hatano S, Ito E, Mori N, Saito H, Kinoshita $\mathrm{T}$ (2002) DNA methylation of p57(KIP2) gene in the promoter region in lymphoid malignancies of B-cell phenotype. Blood 100: 2572-2577

Maiti S, Alam R, Amos CI, Huff V (2000) Frequent association of beta-catenin and WT1 mutations in Wilms tumors. Cancer Res 60: $6288-6292$

Miwa H, Tomlinson GE, Timmons CF, Huff V, Cohn SL, Strong LC, Saunders GF (1992) RNA expression of the WT1 gene in Wilms' tumors in relation to histology. J Natl Cancer Inst 84: 181-187

Moulton T, Crenshaw T, Hao Y, Moosikasuwan J, Lin N, Dembitzer F, Hensle T, Weiss L, McMorrow L, Loew T, Kraus W, Gerald W, Tycko B (1994) Epigenetic lesions at the H19 locus in Wilms' tumour patients. Nat Genet 7: $440-447$

Nakadate H, Tsuchiya T, Maseki N, Hatae Y, Tsunematsu Y, Horikoshi Y, Ishida Y, Kikuta A, Eguchi H, Endo M, Miyake M, Sakurai M, Kaneko Y (1999) Correlation of chromosome abnormalities with presence or absence of WT1 deletions/mutations in Wilms tumor. Genes Chromosomes Cancer 25: 26-32

Nakadate H, Yokomori K, Watanabe N, Tsuchiya T, Namiki T, Kobayshi H, Suita S, Tsunematsu Y, Horikoshi Y, Hatae Y, Endo M, Komada Y, Eguchi H, Toyoda Y, Kikuta A, Kobayashi R, Kaneko Y (2001) Mutations/deletions of the WT1 gene, loss of heterozygosity on chromosome arms 11p and 11q, chromosome ploidy and histology in Wilms' tumors in Japan. Int J Cancer 94: 396-400

Ogawa O, Eccles MR, Szeto J, McNoe LA, Yun K, Maw MA, Smith PJ, Reeve AE (1993) Relaxation of insulin-like growth factor II gene imprinting implicated in Wilms' tumour. Nature 362: 749-751

O'Keefe D, Dao D, Zhao L, Sanderson R, Warburton D, Weiss L, AnyaneYeboa K, Tycko B (1997) Coding mutations in p57 $7^{\text {KIP2 }}$ are present in some cases of Beckwith - Wiedemann syndrome but are rare or absent in Wilms tumors. Am J Hum Genet 61: 295-303

Okamoto K, Morison IM, Taniguchi T, Reeve AE (1997) Epigenetic changes at the insulin-like growth factor II/H19 locus in developing kidney is an early event in Wilms tumorigenesis. Proc Natl Acad Sci USA 94: $5367-5371$

Pritchard-Jones K, Fleming S, Davidson D, Bickmore W, Porteous D, Gosden C, Bard J, Buckler A, Pelletier J, Housman D, vanHeyningen V, Hastie N (1990) The candidate Wilms' tumour gene is involved in genitourinary development. Nature 346: $194-197$

Rainier S, Johnson LA, Dobry CJ, Ping AJ, Grundy PE, Feinberg AP (1993) Relaxation of imprinted genes in human cancer. Nature 362: $747-749$
Reeve AE, Eccles MR, Wilkins RJ, Bell GI, Millow LJ (1985) Expression of insulin-like growth factor-II transcripts in Wilms' tumour. Nature 317: $258-260$

Reik W, Murrell A (2000) Genomic imprinting. Silence across the border. Nature 405: 408-409

Satoh Y, Nakagawachi T, Nakadate H, Kaneko Y, Masaki Z, Mukai T, Soejima H (2003) Significant reduction of WT1 gene expression possibly due to epigenetic alteration in Wilms' tumor. J Biochem (Tokyo) 133: $303-308$

Shin JY, Kim HS, Park J, Park JB, Lee JY (2000) Mechanism for inactivation of the KIP family cyclin-dependent kinase inhibitor genes in gastric cancer cells. Cancer Res 60: 262-265

Soejima H, McLay J, Hatada I, Mukai T, Jinno Y, Niikawa N, Yun K (1998) Comparative RT-PCR and in situ hybridization analyses of human imprinted p57KIP2 and IGF2 gene transcripts in fetal kidney and Wilms tumors using archival tissue. Lab Invest 78: 19-28

Soejima H, Nakagawachi T, Zhao W, Higashimoto K, Urano T, Matsukura S, Kitajima Y, Takeuchi M, Nakayama M, Oshimura M, Miyazaki K, Joh $\mathrm{K}$, Mukai T (2004) Silencing of imprinted CDKN1C gene expression is associated with loss of $\mathrm{CpG}$ and histone $\mathrm{H} 3$ lysine 9 methylation at DMR-LIT1 in esophageal cancer. Oncogene 23: 4380-4388

Soejima H, Yun K (1998) Allele specific-polymerase chain reaction: a novel method for investigation of the imprinted IGF2 gene. Lab Invest 78: $641-642$

Steenman MJ, Rainier S, Dobry CJ, Grundy P, Horon IL, Feinberg AP (1994) Loss of imprinting of IGF2 is linked to reduced expression and abnormal methylation of H19 in Wilms' tumour. Nat Genet 7: 433-439

Taniguchi T, Okamoto K, Reeve AE (1997) Human p57(KIP2) defines a new imprinted domain on chromosome 11p but is not a tumour suppressor gene in Wilms tumour. Oncogene 14: 1201-1206

Thompson JS, Reese KJ, DeBaun MR, Perlman EJ, Feinberg AP (1996) Reduced expression of the cyclin-dependent kinase inhibitor gene p57 ${ }^{\text {KIP2 }}$ in Wilms' tumor. Cancer Res 56: 5723-5727

Wagner KJ, Cooper WN, Grundy RG, Caldwell G, Jones C, Wadey RB, Morton D, Schofield PN, Reik W, Latif F, Maher ER (2002) Frequent RASSF1A tumour suppressor gene promoter methylation in Wilms' tumour and colorectal cancer. Oncogene 21: $7277-7282$

Watanabe N, Nakadate H, Haruta M, Sugawara W, Sasaki F, Tsunematsu Y, Kikuta A, Fukuzawa M, Okita H, Hata J, Soejima H, Kaneko Y (2006) Association of $11 \mathrm{q}$ loss, trisomy 12, and possible $16 \mathrm{q}$ loss with loss of imprinting of insulin-like growth factor-II in Wilms tumor. Genes Chromosomes Cancer 45: 592-601

Yuan E, Li CM, Yamashiro DJ, Kandel J, Thaker H, Murty VV, Tycko B (2005) Genomic profiling maps loss of heterozygosity and defines the timing and stage dependence of epigenetic and genetic events in Wilms' tumors. Mol Cancer Res 3: 493 -502

Yun K, Soejima H, Merrie AE, McCall JL, Reeve AE (1999) Analysis of IGF2 gene imprinting in breast and colorectal cancer by allele specific-PCR. J Pathol 187: 518-522 